\title{
AS COMISSÕES PRÓPRIAS DE AVALIACCÃO FRENTE AO PROCESSO DE REGULAÇÃO DO ENSINO SUPERIOR PRIVADO
}

\author{
Breno Pádua Brandão CARneiro* \\ Ivan LuIZ NovaEs**
}

Recebido em: 31 de dezembro de 2007

Aprovado em: 22 de setembro de 2008

\begin{abstract}
* Mestre em Educação pela Universidade do Estado da Bahia -UNEB. Membro do Núcleo de Estudos e Pesquisas em Gestão Educacional e Formação de Gestores - NUGEF. E-mail: brenopbc@gmail.com.

** Prof. Dr. do Programa de Pós-graduação em Educação e Contemporaneidade Universidade do Estado da Bahia - UNEB. Coordenador do Núcleo de Estudos e Pesquisas em Gestão Educacional e Formação de Gestores - NUGEF. E-mail: ivanovaes@gmail.com
\end{abstract}

Resumo: Este artigo visa apresentar os principais resultados obtidos a partir da pesquisa realizada entre as Comissões Próprias de Avaliação das Instituições de Ensino Superior privadas em SalvadorBahia. A pesquisa destinou-se à análise da percepção dos coordenadores de Comissões Próprias de Avaliação acerca da participação e da avaliação no processo de regulação requerido pelo Sistema Nacional de Avaliação. Para tanto, exploramos leis, decretos, portarias, etc. - relativos ao ensino superior, bem como procedemos à revisão bibliográfica sobre o tema, enfatizando os conceitos de regulação, participação e avaliação. Utilizamos um instrumento de coleta de dados a partir da elaboração de um questionário, cuja base referencial teórico-metodológico contempla e demarca conceitualmente o objeto de investigação. Por fim, analisamos as informações coletadas, com o intuito de identificar e correlacionar as principais dimensões - participação e avaliação - constantes do quadro teórico.

Palavras-chave: Regulação. Ensino Superior. Participação. Avaliação.

\section{THE INTERNAL EVALUATION COMMITTEES AND THE REGULATION PROCESS OF PRIVATE HIGHER EDUCATION INSTITUTIONS}

Abstract: The purpose of this essay is to present the main results obtained in an exploratory study conducted by the Internal Evaluation Committees of the Private Higher Education Institutions in the capital of the State of Bahia. The research analyzed relevant aspects of the perception of the coordinators of Internal Evaluation Committees concerning the participation and evaluation in the process of regulation required by the National Evaluation System. With this purpose, we analyzed documents relative to higher education, such as laws, decrees and directives, as well as proceeded with a bibliographical review on higher education, especially the concepts of regulation, participation and evaluation. The data was collected using a questionnaire based on the theoretical and methodological approaches that conceptually mark the object of the investigation. Then, we analyzed the information collected with the purpose of identifying and correlating the main dimensions involved - participation and evaluation.

Key words: Regulation. Higher Education. Participation. Evaluation. 
O processo de regulação das políticas e serviços privados passou a se constituir, nas atuais conjunturas internacional e local, num mecanismo que desperta grande interesse, tanto das forças econômicas internacionais quanto dos Estados Nacionais. No campo educacional, o referido processo se apresenta associado a quatro fatores que impulsionam as rápidas transformações: (i) o impacto das novas tecnologias no meio produtivo, (ii) a entrada de novos atores no campo educacional, (iii) o aumento da competitividade (iv) e a influência mundial sobre o ensino superior.

O aumento acentuado da oferta de ensino superior privado se insere no contexto dessas transformações. O súbito incremento desse setor, por outro lado, vem suscitando reflexões teóricas acerca do tratamento que deve receber, por parte do Estado, no âmbito das políticas públicas de educação, especialmente no que tange ao controle e à regulação.

\section{Desenvolvimento e Educação na Contemporaneidade}

$\mathrm{O}$ contexto das recentes transformações ensejou um amplo leque de tendências e possibilidades no que diz respeito às políticas educacionais para o Ensino Superior, notadamente a partir de orientações emanadas das agências multilaterais de fomento ao desenvolvimento. O Banco Mundial (BIRD), por exemplo, em documento intitulado "La Enseñanza Superior: Las Lecciones Derivadas de la experiencia", apresenta quatro orientações principais no que diz respeito à reforma educacional no nível superior de ensino:

(i) Fomentar a maior diferenciação das instituições, incluindo o desenvolvimento de instituições privadas; (ii) Proporcionar incentivos para que as instituições públicas diversifiquem as fontes de financiamento, por exemplo, a participação de estudantes nos gastos e a estreita vinculação entre financiamento fiscal e resultados; (iii) Redefinir a função do governo no ensino superior; (iv) Adotar políticas destinadas a priorizar os objetivos de qualidade e eqüidade. (BIRD, 1995, p. 4, grifos nossos).

As orientações contidas no documento acima referido identificam na iniciativa privada um setor com grande potencial para atuar no ensino superior, constituindo "elemento importante de alguns dos sistemas de ensino pós-secundário mais eficientes que existem atualmente no mundo em desenvolvimento". Sugere, ainda, que o Estado deve migrar de uma posição de controle direto do sistema de ensino superior para o oferecimento de um ambiente de políticas favoráveis às instituições (BIRD, 1995, p. 6). 
No contexto em que se combinam o incentivo ao setor privado e a retração do Estado, o Banco Mundial orienta pela ampliação de "oportunidades educacionais com pouco ou nenhum custo para o Estado", proporcionando e ampliando a participação social no ensino superior. (BIRD, 1995, p. 6).

Seguindo tendência semelhante à indicada pelo Banco Mundial, a Organização Mundial do Comércio (OMC) incluiu, em 1999, a educação entre os serviços que devem ser regulados pelo Acordo Geral sobre Comércio em Serviços (AGCS) - GATTS em sua sigla em inglês. Esse acordo multilateral, aprovado pelos estados membros da OMC, em 1994, prevê a liberalização progressiva de serviços em âmbito transnacional. A perspectiva da OMC é transformar o campo educacional em setor comercial de abrangência global, regido essencialmente pelas forças do mercado.

A orientação de políticas educacionais a partir de demandas de mercado, contudo, vem suscitando alguma polêmica. Silva Junior (2005), por exemplo, entende que o paradigma proposto pelas agências multilaterais, como é o caso do Banco Mundial e da OMC, caracteriza uma visão de desenvolvimento em que a educação não tem por objetivo elevar a condição humana, mas se constituir num instrumento de adaptação à realidade e conseqüente sobrevivência em sua configuração presente.

De fato, alguns países têm se manifestado de forma contrária à inclusão da educação como serviço regulado pelo mercado internacional, conforme propõe o AGCS. O Japão, por exemplo, defende a necessidade de manter mecanismos governamentais de controle da oferta educacional, com o intuito de proteger valores culturais locais. Já os países da Comunidade Européia divulgaram, em 2003, uma lista com os serviços excluídos da possibilidade de negociação no comércio internacional, dentre os quais a educação (HADDAD; GRACIANO, 2004).

A manutenção do ensino superior sob controle dos Estados Nacionais reflete o entendimento de que a educação, mesmo quando oferecida por instituições privadas, se reveste de natureza pública. Esse entendimento se coaduna com a visão de Ranieri (2000), que considera que o ensino superior assume natureza pública em face dos benefícios que produz, e não devido ao fato de ser oferecido diretamente pelo Estado.

A partir das perspectivas apresentadas, podemos compreender que a educação representa estratégia fundamental para o desenvolvimento, não devendo, assim, regular-se apenas a partir do mercado. Sob tal ótica, uma estratégia política pode ser considerada, qual seja, a constituição de mecanismos de regulação da atividade educacional pelos Estados nacionais, com vistas à promoção de transparência e à oferta de cursos levando em conta a necessidade social. 


\section{Estado e Educação Superior}

No campo educacional brasileiro, a expansão privada, principalmente no ensino superior, vem se constituindo de alta relevância para estudos e pesquisas sobre o processo de regulação deste setor pelo Estado. Há algum tempo, a convergência de investimentos governamentais diretos incide principalmente nos níveis fundamental e médio de ensino. É possível observar que a participação da iniciativa privada é minoritária em ambos. Em relação ao ensino superior, todavia, a situação se inverte.

Entre 1994 e 2004, por exemplo, o número de estudantes matriculados em cursos de graduação cresceu em 250,67\%, passando de 1.661 .034 para 4.163.733. Uma expansão localizada notadamente no setor privado de ensino, que responde por $71,7 \%$ das matriculas em cursos de graduação (BRASIL, 2005).

Para melhor compreender como se configurou este quadro de intensa expansão privada no campo educacional, buscaremos explorar, ainda que de maneira sucinta, o desenvolvimento histórico do processo de consolidação do sistema de ensino superior brasileiro. Nossa exploração terá como foco principal a relação entre regulação estatal, setor privado e sociedade.

\section{Regulação e Expansão do Ensino Superior Privado}

A expansão privada no ensino superior brasileiro configurou-se de forma mais acentuada entre as décadas de 1960 e 70, vindo a sofrer novo impulso mais recentemente, a partir de meados dos anos 90. A tradição no Brasil, de acordo com Cunha (2004), aponta a prevalência do ensino estatal e centralmente controlado. Essa característica, segundo o autor, permeou o ensino superior brasileiro desde o Império até o início do século XX.

Sampaio (2000) identifica nas estatísticas oficiais dois períodos claramente distintos, no que tange à expansão do ensino superior privado: o primeiro compreende o período entre 1933 e 1965 e o segundo, entre 1965 e $1980 . \mathrm{Na}$ perspectiva da autora, o primeiro caracteriza-se pela consolidação e estabilidade da participação do setor privado no sistema de ensino superior. O segundo corresponde ao incremento do crescimento do setor no sistema, que passa a ser predominante em relação ao ensino público.

Com efeito, o censo educacional realizado em 1933 indica que o setor privado, àquela época, demonstrava sinais de expansão, sendo responsável por 43,7\% das matrículas no ensino superior. De acordo com Sampaio (2000), embora o 
sistema de ensino superior tivesse ampliado gradualmente o número de vagas em instituições públicas e privadas, a demanda parecia crescer em proporção maior que a capacidade de oferta.

Esse descompasso se tornou mais evidente a partir da década de 1960, quando se consolida o aparato normativo mais consistente visando orientar a regulação do sistema de ensino superior. A partir desse aparato normativo, a relação entre regulação e expansão privada assumiu características que permearam, de forma marcante, o desenvolvimento do sistema de ensino superior.

Nesse contexto, dois marcos legais se destacaram: as Leis $n^{\circ}$ 4.024/61 (Lei de Diretrizes e Bases - LDB) e no 5.540/68 (Reforma Universitária). Na perspectiva de Sampaio (2000), a novidade da $\mathrm{LDB} / 61$, no que se refere ao ensino superior, voltava-se para a regulamentação dos mecanismos de expansão desse nível de ensino, estabelecendo nova sistemática.

ALDB/61 atribuiu ao CFE a competência para "decidir sobre o funcionamento dos estabelecimentos isolados de ensino superior, federais ou particulares", bem como "sobre o reconhecimento das Universidades [...] e dos estabelecimentos isolados" (Lei no 4.024/61; Art 9, alíneas a e b).

Em relação à composição do referido Conselho e sua articulação com a sociedade civil organizada, contudo, a Lei é pouco precisa e não fixa proporção ou critérios mais objetivos de escolha que garantissem o envolvimento e a participação da sociedade. Essa lacuna terminou por proporcionar a composição de um conselho identificado com o meio empresarial educacional.

A reforma universitária (Lei $\mathrm{n}^{\circ} 5.540 / 68$ ) vem complementar a LDB/61 fixando moldura legal mais definida quanto ao ordenamento do ensino superior. Ranieri (2000) observa que a reorganização do sistema de ensino superior era, de fato, necessária naquele momento. A expansão desordenada, decorrente da aglomeração de escolas isoladas, sem o necessário sentido de integração em um conjunto mais amplo, fragilizava o sistema. As previsões e intenções contidas na Lei da reforma, contudo, não alteraram essa situação na visão da autora.

A reforma teve como um de seus principais objetivos implantar o modelo universitário ancorado na relação entre ensino e pesquisa, já consagrado em outros países. Efetivamente, o modelo proposto seria reproduzido nas Universidades públicas, enquanto as instituições de ensino mantidas pela iniciativa privada se firmam e se proliferam nos moldes da excepcionalidade.

Uma apreciação mais detida sobre o teor da Lei da reforma (Lei $\left.{ }^{0} 5.540 / 68\right)$ evidencia, de um lado, grande atenção no que se refere à forma de organização e controle das instituições Federais. De outro, deixa em aberto a forma pela qual se estabelecerão as IESP. Esse modelo de regulação se apresenta, assim, 
de forma pouco prospectiva quanto ao planejamento do sistema e à perspectiva de participação social em sua gestão, especialmente em relação ao setor privado.

Tal fragilidade torna evidente a partir da evolução das normas legais que respaldaram a atuação do CFE no que diz respeito à expansão do ensino superior. Na visão de Tramontin e Braga (apud SAMPAIO, 2000), a análise do aparato normativo - decretos, resoluções e pareceres - emanados do CFE ao longo da década de 70 , até meados dos anos 80 :

parece mostrar a crise de objetivos que afeta os órgãos responsáveis pela política de ensino superior. Os contínuos avanços e recuos das normas e ritos sugerem [...] a insegurança sobre o que se quer e até onde chegar em matéria de ensino superior. Tem-se a nítida impressão de que o procedimento se efetua mais por "tentativa e erro" do que referência a objetivos explícitos. (TRAMONTIN; BRAGA, apud SAMPAIO, 2000, p. 65)

A pouca clareza no que se refere à definição de políticas para o ensino superior não se estabeleceu sem conseqüências. Os incentivos diretos e indiretos à iniciativa privada, aliados à representação majoritariamente privatista do CFE, proporcionaram a inversão da predominância das IES públicas no sistema, que passaram a ser minoritárias em relação à proporção de estudantes matriculados. Tal quadro legou, ainda, um aparato regulatório pouco eficaz, baseado mais no lobby empresarial do que em critérios voltados para o interesse público.

\section{Regulação e Avaliação no Governo Fernando Henrique Cardoso}

Após um período de ampla expansão entre as décadas de 1960 e 70, o ensino superior privado chega aos anos 80 com relativo arrefecimento e estagnação. De acordo com dados fornecidos pelo INEP, as matrículas no setor, que representavam $64,3 \%$ do total em 1980 , passaram a responder por $58,4 \%$ em 1994 , indicando um percentual negativo de crescimento em relação ao sistema.

Enquanto na década de 70 a atenção primordial voltava-se para a acomodação da demanda crescente pelo ensino superior, nos anos 80 a atenção destinava-se à questão da coordenação do sistema educacional. Explorava-se, principalmente sobre o planejamento, administração, alocação de recursos e centralização do controle com abertura à participação (SAMPAIO, 2000).

A partir de meados dos anos 90, contudo, a política estabelecida na gestão do presidente Fernando Henrique Cardoso (FHC) restabeleceu a tendência de 
expansão privada. Nesse sentido, o governo FHC manteve e, em certa medida, acentuou as políticas de reforma do Estado que vinham sendo incrementadas desde o início dos anos 80. Na visão de Silva Junior (2005), a política de reforma desse governo redesenhou o Estado e a sociedade civil, prospectando para o primeiro a condição de Estado enxuto e forte, sob o domínio de uma ideologia gerencial, e gerando um novo paradigma de políticas públicas, cuja oferta se dá no âmbito da sociedade civil.

Com efeito, no campo do ensino superior, o quadro de reforma do Estado promovido pelo governo vem a se materializar na instituição de uma política de capitalismo concorrencial, voltada para a equalização das condições de concorrência do setor privado (CUNHA, 2003). A política de incentivos diretos e indiretos à iniciativa privada é, dessa forma, substituída por um tipo de política onde o Estado atua com maior ênfase na supervisão, acompanhamento e controle do sistema de ensino superior, numa linha semelhante à indicada pelo Bird.

No torvelinho da reorientação das políticas para o ensino superior, o governo adota uma série de medidas relacionadas à regulação com o intuito de promover mudanças estruturais no sistema. A primeira medida adotada, que ilustra com propriedade o tipo de mudança pretendida, diz respeito à extinção do CFE, que vinha sofrendo críticas e pressões de diversos setores da sociedade em decorrência de sua atuação muito centrada no lobby empresarial.

O CFE acumulava, na década de 90, um excesso de atribuições que the haviam sido delegadas, caracterizando a independência do órgão em relação ao poder central. Sob esse prisma, Sampaio (2000) sugere que o principal motivo de sua extinção teve como propósito centralizar o poder decisório do MEC, restaurando, assim, a capacidade do Ministério no que diz respeito ao delineamento de políticas para a área.

A Lei $\mathrm{n}^{\circ}$ 9.131/95, que altera dispositivos da LDB/61, revoga as atribuições e competências do CFE, extingue o mandato de seus membros, ao tempo em que institui o Conselho Nacional de Educação (CNE), composto pelas Câmaras de Educação Básica e de Educação Superior, como órgão de assessoramento do Ministério da Educação (MEC).

A questão em torno da forma de composição do CNE, contudo, gerou grande polêmica e ensejou diversas reformulações a partir de portarias e decretos. Do ponto de vista de alguns autores (SAMPAIO, 2000; NUNES, 2002), mesmo com tais reformulações o Conselho terminou por se caracterizar como um órgão de representação de interesses corporativos diversos, por vezes inconciliáveis, que se sobrepunham aos interesses comuns da educação nacional. 
A despeito das circunstâncias de sua trajetória, Nunes (2002) avalia que o CNE se apresenta de forma significativa no contexto educacional da época. Mesmo com certa tendência à microrregulação, o autor considera que a atuação do Conselho contribuiu para a flexibilização das políticas de ensino superior.

No que tange às atribuições de regulação do CNE, a Lei n ${ }^{\circ}$ 9.131/95 confere à Câmera de Educação superior (CES), dentre outras funções, a de deliberar sobre os relatórios de reconhecimento de cursos, bem como sobre a autorização, o credenciamento e o recredenciamento periódico das IES, com base em relatórios e avaliações apresentados pelo MEC. Apresenta-se pela primeira vez, nesse momento, a intenção do governo em alinhar os processos de regulação e avaliação do ensino superior.

A nova Lei de Diretrizes e Bases (Lei no 9.394/96) vem reforçar a relação entre regulação e avaliação. Em seu art. 46 , ficam condicionados os processos de autorização e reconhecimento de curso, bem como o credenciamento de IES, a instrumentos regulares de avaliação. Nesse contexto, em 1996, surge como um dos principais instrumentos de avaliação o Exame Nacional de Cursos (ENC), também conhecido como "Provão".

A articulação entre regulação e avaliação viria a se constituir, posteriormente, como uma das principais características da política educacional para o ensino superior naquele governo. Em documento intitulado "Políticas e resultados, 1995-2002 - Ensino superior maior e melhor", publicado pelo MEC (2002) ao final do segundo mandato de $\mathrm{FHC}$, a redefinição da "essência da relação entre Estado e o sistema de ensino superior" (p. 8) é identificada como primeira linha de atuação do Ministério durante a gestão que se encerrava naquele momento. Esta redefinição, de acordo com o documento, se estabelecia pela diminuição da simples ação credenciadora articulada ao aumento da função avaliadora exercida pelo Estado (p. 11).

As políticas do governo FHC indicam, portanto, a intenção de promover a atuação do Estado com vistas a consolidar um modelo de regulação voltado à interação com outros agentes reguladores, como, por exemplo, o mercado. Nesse sentido, a análise das normas legais sugere a intenção do governo em prover a oferta de ensino superior, em grande medida, a partir do setor privado.

Em linhas gerais, podemos dizer que duas características principais marcaram a política de ensino superior do governo FHC. A primeira diz respeito ao incentivo à expansão privada, o que pode ser evidenciado pelo elevado incremento do número de matrículas no setor. Entre 1995 e 2002, as matrículas 
em instituições privadas passaram de 1.059.163 para 2.428.258, representando uma taxa de crescimento na razão de $229 \%$ (INEP/MEC). A segunda, e mais significativa para o presente estudo, se refere ao esforço do governo em estabelecer um aparato normativo de regulação que visava se alinhar aos principais processos avaliativos.

Desta maneira, o governo FHC encerra o mandato deixando para seu sucessor políticas destinadas à regulação do sistema de ensino superior e um quadro caracterizado pelo reaquecimento da expansão de cursos e de instituições de ensino superior privadas. É importante sublinhar que tal expansão se diferenciou daquela ocorrida nas décadas de 60 e 70 em razão do estabelecimento de políticas voltadas para regular a oferta a partir da avaliação dos cursos, destacando-se, nesse sentido, o "Provão" como principal instrumento de avaliação.

\section{O Sistema Nacional de Avaliação do Ensino Superior}

Sob a gestão do governo Lula, o MEC imprime um processo de revisão das políticas de regulação do sistema de ensino superior. Embora incorporando novos elementos, mantém certa linha de continuidade no que se refere ao empenho em desenvolver um modelo com ênfase na avaliação.

As medidas adotadas pelo governo destinam-se à ampliação do arcabouço legal voltado para a regulação do ensino superior, através da articulação entre instrumentos de planejamento, gestão e avaliação institucional. Com efeito, a principal medida adotada foi a implantação do Sistema Nacional de Avaliação do Ensino Superior (SINAES), a partir da Lei no 10.861/04.

A Lei (SINAES) acima referida estabelece como objetivo "assegurar a avaliação das instituições de educação superior, dos cursos de graduação e do desempenho acadêmico de seus estudantes" (art. $1^{\circ}$ ). Dentre as finalidades atribuídas ao SINAES destacamos "a melhoria da qualidade da educação superior, a orientação da expansão da sua oferta" ( $\left(1^{\circ}\right.$ do art. $1^{\circ}$ da Lei ${ }^{\circ}$ 10.861/04). A partir das finalidades, fica clara a intenção do MEC em atribuir ao sistema de avaliação a responsabilidade sobre a regulação do sistema de ensino superior.

De acordo com o documento "Diretrizes para a Avaliação das Instituições de Educação Superior” (BRASIL. MEC, 2004), que visa sistematizar a concepção, princípios e dimensões postulados pelo SINAES, uma das características fundamentais do novo sistema de avaliação consiste na centralidade da avaliação institucional no processo avaliativo. 
Em relação aos procedimentos para a avaliação institucional, dois aspectos são considerados principais, conforme define o $\S 2^{\circ}$ do artigo $3^{\circ}$ da Lei $n^{\circ}$ 10.861/04: a auto-avaliação e a avaliação externa in loco. A auto-avaliação consiste num "processo desenvolvido por membros internos e externos de uma dada comunidade acadêmica, visando promover a qualidade acadêmica" (BRASIL. MEC, 2004, p. 4). Já a avaliação externa in loco representa um processo documental e a verificação, in loco, das condições acadêmicas, realizada por especialistas selecionados.

$\mathrm{Na}$ promoção da avaliação deverão ser assegurados, conforme estipula o art. $2^{\circ}$ da Lei $n^{\circ} 10.861 / 04$, o caráter público dos procedimentos, dados e resultados, bem como a ampla participação, por meio de representações, de todos os segmentos da comunidade acadêmica e da sociedade civil. $\mathrm{O}$ artigo dessa Lei denota a intenção do governo em estabelecer um sistema de avaliação que incorpore a participação social, constituindo-se na base para a regulação.

A participação social pretendida pelo SINAES assenta-se sobre uma estrutura composta pela Comissão Nacional de Avaliação da Educação Superior (CONAES), órgão colegiado de coordenação e supervisão (art. $6^{\circ}$ Lei n ${ }^{\circ} 10.861 / 04$ ), e por Comissões Próprias de Avaliação (CPA), responsáveis por desenvolver a auto-avaliação no âmbito de cada IES (art. 11 da Lei $n^{\circ}$ 10.861/04). Essa estrutura prevê, ainda, o Instituto Nacional de Estudos e Pesquisas Educacionais Anísio Teixeira (INEP) como órgão responsável por realizar a avaliação externa das instituições, dos cursos e dos estudantes.

No que diz respeito à articulação das CPAs com a CONAES e sua participação no sistema de avaliação, o art. 11 da Lei $n^{0}$ 10.861/04 estabelece que cada IES deverá constituir sua comissão, responsável pela condução dos processos de auto-avaliação, cujos resultados deverão ser sistematizados e encaminhados à CONAES sob forma de relatório. Quanto à composição das CPAs, as IES deverão assegurar a "participação de todos os segmentos da comunidade universitária e da sociedade civil organizada". O artigo da Lei visa estabelecer, ainda, certo equilíbrio na composição ao indicar que não devem ser privilegiados na comissão quaisquer dos segmentos com maioria absoluta (Lei ${ }^{\circ} 10.861$; art. 11 inciso I).

A composição de uma comissão (CPA) com representação da sociedade, cuja atribuição destina-se a conduzir o processo de auto-avaliação no âmbito das IES, certamente representa grande impacto na gestão, principalmente das instituições privadas, marcadas historicamente pelo isolamento no que se refere a um acompanhamento mais direto do Estado e da Sociedade. 


\section{Articulação Entre o Sistema de Avaliação e o Processo de Regulação}

É importante destacar no cenário do sistema de avaliação das IES o Decreto $\mathrm{n}^{0} 5.773 / 06$, à medida que este define as funções de regulação, supervisão e avaliação de IES. Quanto à articulação entre regulação e avaliação, o referido decreto estabelece que:

A avaliação realizada pelo Sistema Nacional de Avaliação da Educação Superior - SINAES constituirá referencial básico para os processos de regulação e supervisão da educação superior, a fim de promover a melhoria de sua qualidade ( $\left(3^{\circ}\right.$ do art $1^{\circ}$; grifo nosso).

O processo de regulação, conforme estipula o artigo 10 do decreto acima referido, se dará por meio de atos autorizativos, compreendidos pelo credenciamento e recredenciamento de IES, bem como autorização, reconhecimento e renovação de reconhecimento de cursos. Nesse sentido, os referidos atos deverão ter deferimento condicionado à demonstração do funcionamento regular da instituição com base na avaliação do SINAES. Ficam, ainda, condicionados os pedidos de renovação de reconhecimento de curso à conclusão de cada ciclo avaliativo do SINAES.

Embora o referido decreto estabeleça, em linhas gerais, formas de articulação entre a regulação e a avaliação, é patente a ausência quanto à definição de responsabilidades mais diretas das instâncias que privilegiam a participação social no âmbito do SINAES, notadamente CONAES e CPA. Com efeito, recai sobre o INEP a centralidade na condução e no acompanhamento dos atos autorizativos.

O modelo de regulação implantado a partir do Decreto $n^{0} 5.773 / 06$, embora estabeleça a avaliação como principal referencial do processo regulatório, demonstra certo distanciamento no que tange à participação social. Evidenciase, portanto, a importância de ampliar o campo da investigação em torno do funcionamento das CPAs no processo de regulação das IES privadas, objetivo central desta pesquisa, especialmente, ante a nova dinâmica estabelecida oficialmente, através da institucionalização das CPAs como órgãos de mediação entre IES e sistema de avaliação.

\section{A Perspectiva da Regulação}

Observa-se que o conceito de regulação vem sendo utilizado para identificar a intervenção de instâncias com autoridade legítima, em geral de natureza 
estatal, com intuito de coordenar e orientar a ação de agentes econômicos. A regulação, nesse caso, abrange as dimensões de coordenação, controle e influência exercidos pelo Estado sobre os sistemas econômicos e sociais, inserindo-se assim como mecanismo importante das políticas públicas, especialmente no contexto de alteração dos modos de intervenção estatal. Sua importância vem à tona quando, de um lado, assistimos à tentativa de assegurar ao Estado papel relevante na definição, pilotagem e execução das políticas públicas e, de outro, esse papel passa a ser cada vez mais compartilhado com novos agentes e atores sociais (BARROSO, 2006).

No contexto da redefinição de papéis dos atores envolvidos no desenvolvimento das políticas públicas, Barroso (2006) identifica três níveis distintos de atuação no campo da regulação: regulação transnacional, regulação nacional e microrregulação local. Esses três níveis interagem de forma articulada, de modo a constituir um sistema complexo e multifacetado.

A regulação transnacional diz respeito ao conjunto de normas, discursos e instrumentos produzidos e difundidos nos fóruns de decisão e consulta internacionais, e que terminam por ser assimilados em nível nacional. Esse nível de influência, segundo Barroso (2006), pode se manifestar de diversas formas, desde a influência direta dos países centrais, através de constrangimentos estruturais que integram os chamados "efeitos da globalização", até a ação mais sutil dos organismos internacionais, via programas de cooperação e desenvolvimento.

A regulação nacional compreende o modo como as autoridades públicas exercem a coordenação, o controle e a influência sobre os sistemas econômicos e sociais, orientando, através de aparato normativo, a ação dos diferentes atores sociais e seus resultados. $\mathrm{Na}$ atualidade, assistimos à emergência de novos modos de regulação nacional, provocada, em grande parte, pela influência da regulação transnacional, e de mutações políticas e sociais que provocam a degeneração dos modos tradicionalmente estabelecidos (BARROSO, 2006).

Por fim, a microrregulação local remete a um complexo jogo de negociações e estratégias que envolve vários atores no reajuste local das contingências da regulação nacional. Barroso (2006) define esse tipo de regulação como o processo de coordenação da ação dos atores locais no confronto e negociação de diferentes interesses, lógicas e racionalidades.

No que se refere ao nível da regulação nacional tornou-se comum referir-se ao desenvolvimento do "Estado regulador". Essa expressão passou a ser utilizada para caracterizar a proliferação de agências reguladoras que passaram a representar o interesse público em nome do governo quando se trata de assuntos sociais e econômicos (KING, 2006). 


\section{O Estado Regulador}

A referência ao Estado regulador articula-se ao movimento da reforma do Estado e sua modernização. A regulação, nesse contexto, aparece sempre associada a uma imagem menos prescritiva e burocrática do Estado, reforçando o conceito de uma "nova administração pública", que substitui o controle direto - a priori - sobre os processos por um controle remoto - a posteriori - baseado em resultados (BARROSO, 2005).

Considera-se que a reforma ou reconstrução do Estado, especialmente por meio da reforma gerencial da administração pública, visa responder ao processo de globalização em curso. Esse processo de reforma é criticado por reduzir a autonomia dos Estados na formulação e implementação de políticas. Na perspectiva de Bresser-Pereira (1998), essa reforma parte do pressuposto de que a atuação do Estado em algumas áreas, especialmente, social e científica, pode ser mais eficiente a partir da utilização de outras instituições e da implementação de estratégias gerenciais na execução de serviços.

O Estado, portanto, passa a atuar, no contexto da reforma, com sentido gerencial, monitorando resultados - controle a posteriori - e estimulando a competição administrativa entre entidades às quais foi garantida autonomia. "Na administração pública gerencial, o controle de resultados substitui o controle de procedimentos legais" (BRESSER-PEREIRA, 1998, p. 147).

À medida que atribui ao mercado certa autonomia, o objetivo principal da reforma, de acordo com Bresser-Pereira, visa dotar o Estado de condições para que seus governos possam enfrentar falhas produzidas no âmbito do mercado. Em outras palavras, a reforma visa incrementar a governabilidade por parte do Estado, de modo a complementar o mercado na coordenação da economia, ao tempo em que busca promover a distribuição de renda mais justa.

\section{Regulação no Ensino Superior: Tendências}

No campo do ensino superior, observa-se que o Estado vem enfrentando dificuldades crescentes para exercer o papel de controle estreito que desempenhava até pouco tempo. Essa dificuldade se apresenta ante o grau de complexidade dos desafios ao desenvolvimento do ensino superior, notadamente frente à expansão privada. Em conseqüência, as IESP, por todo o mundo, se encontram sujeitas ao jogo do mercado.

Do ponto de vista teórico, Agasisti e Catalano identificam dois modelos ideais de gestão para os sistemas universitários: o modelo do mercado e o modelo centralista. No primeiro caso, as IES definem seus próprios preços e atuam sem 
intervenção pública. Esse modelo, na ausência de qualquer tipo de avaliação, sofre problemas relacionados à assimetria de informações.

Já no modelo centralista, o Estado financia e exerce o controle central do sistema de ensino superior. De acordo com Agasisti e Catalano, a principal crítica em relação a esse modelo questiona a eficiência e habilidade do governo central em lidar com um sistema articulado e complexo como o de ensino superior. Na prática, todavia, o mais comum é a forma intermediaria entre esses dois modelos.

Barroso (2005) utiliza-se dos estudos comparativos sobre tendências das políticas educacionais no Canadá, EUA, França e Reino Unido, realizados por Lessard, Brassard \& Lusingnan, a fim de exemplificar como o conceito de regulação tem sido aplicado no contexto do ensino superior:

O Estado não se retira da educação. Ele adota um novo papel, o do Estado regulador e avaliador que define as grandes orientações e os alvos a atingir, ao mesmo tempo em que monta um sistema de monitoração e de avaliação para saber se os resultados desejados foram, ou não, alcançados. [...] Ele abandona parcialmente a organização e a gestão quotidiana, funções que transfere para os níveis intermediários e locais, em parceria e concorrência com atores privados. (LESSARD; BRASSARD; LUSINGNAN apud BARROSO, 2005, p. 732).

\section{Regulação e Participação}

Em sua análise sobre o Estado regulador do ensino superior, King (2006) observa que uma forte tendência nas políticas de regulação do setor caracterizada pelo estabelecimento de reguladores intermediários, ou seja, grupos-chave que atuam na interface entre regulador e regulado. Essa tendência converge para um processo de distribuição da autoridade reguladora entre grupos qualificados da sociedade.A perspectiva da regulação intermediada pela sociedade traz à tona a questão da participação, ensejando uma exploração mais detida deste conceito.

O termo participação é utilizado de forma cotidiana para designar qualquer situação em que há o mínimo de interação, em muitos casos indicando apenas a presença de um indivíduo em uma atividade de grupo. Pateman (1970), contudo, observa que na sociedade industrial o uso do termo participação aparece associado à alteração de uma estrutura ortodoxa de autoridade, em graus mais ou menos elevados. Nesse sentido, a participação relaciona-se ao envolvimento do indivíduo na tomada de decisões que dizem respeito ao seu trabalho ou à sua condição pessoal, de um modo geral. 
No campo político, a participação pode assumir três formas ou níveis, de acordo com Sani (apud BOBBIO; MATEUCCI; PASQUINO, 2002). Podemos designar a primeira de presença, uma forma superficial de participação que compreende comportamentos passivos em que o indivíduo não contribui pessoalmente. A segunda compreende o que o autor denomina ativação. Um tipo de atuação voltado para promover atividades com o intuito de difundir organizações ou ideais políticos.

A terceira, e mais significativa para o presente estudo, se refere à participação propriamente dita. Na visão de Sani (apud BOBBIO; MATEUCCI; PASQUINO, 2002), o termo tomado em seu sentido estrito designa as situações em que os indivíduos atuam na tomada de decisão política. Em geral, esse tipo de participação se estabelece de forma indireta, podendo ensejar a atuação direta em contextos políticos específicos envolvendo um número restrito de pessoas.

Dois aspectos principais podem influenciar a participação: as estruturas ou ocasiões de participação política e a motivação para tomar parte nestas. Em ambos os casos, o contexto político-cultural é bastante significativo, sendo encontradas condições mais favoráveis à participação em sistemas democráticos de governo (SANI apud BOBBIO; MATEUCCI; PASQUINO, 2002).

\section{Avaliação e Ação Participativa}

É de suma importância, para compreender as transformações da educação superior nos últimos anos, considerar os processos adotados em torno da avaliação. As grandes mudanças promovidas no Estado, em geral, pautam-se na avaliação como agente propulsor de reformas. Na perspectiva de Dias Sobrinho (2004), tanto a educação superior quanto a avaliação representam fenômenos sociais que cumprem determinados papéis, e respondem às demandas que se impõem a partir das circunstância históricas. A partir da perspectiva de Dias Sobrinho, há dois paradigmas ou enfoques principais em torno da avaliação: a epistemologia objetivista e a epistemologia subjetivista. O primeiro diz respeito à avaliação entendida como controle e tem como objetivo a verificação e a medida da conformidade. Trata-se, na visão do autor, de um paradigma conservador e voltado para o passado. O segundo, aborda a avaliação como ação de atribuição de valor e produção de sentidos. Sua base, conforme sustenta o autor, "é o real, porém não simplesmente como produção passada e sentido já acabado, mas, sobretudo, como projeto aberto ao futuro" (p. 723).

No caso brasileiro, o modelo de avaliação vigente no ensino superior encontra-se em processo de transição. De modo geral, podemos atribuir dois 
objetivos principais a esse modelo: (i) aferir critérios de qualidade às IES, de modo a qualificar a sociedade, através de amplo processo de informação, no que diz respeito à escolha de um curso/instituição superior; (ii) e promover a qualidade no âmbito do sistema de ensino superior.

Do ponto de vista da adequação estrita deste modelo a um dos dois paradigmas sugeridos por Dias Sobrinho, observa-se certa ambigüidade, à medida que os objetivos expostos acima ensejam aspectos relacionados às duas tendências. Devemos levar em conta que a distinção feita pelo autor se dá a partir de modelos ideais.

Com efeito, os instrumentos avaliativos que visam orientar objetivamente a opção do público baseiam-se fundamentalmente em critérios objetivos de comparação, enquadrando-se no campo da epistemologia objetivista. Já a perspectiva de promover melhoramentos no sujeito da avaliação reflete a tendência subjetivista.

Quanto a esta última tendência, podemos entender melhor a sua expressão através da abordagem formativa de avaliação. $\mathrm{O}$ objetivo da avaliação formativa, na perspectiva de Bonniol e Vial (2001), destina-se à regulação, em oposição ao da avaliação somativa que persegue apenas o controle. Enquanto essa última busca medir critérios de qualidade de modo a aferir uma grandeza de valor que determina a aderência a critérios pré-estabelecidos, a primeira volta-se aos procedimentos, ao processo de construção do referencial do sujeito avaliado, ensejando o seu desenvolvimento. Evidencia-se, assim, a importância de estudos que aprofundem a compreensão em torno da avaliação e da participação no contexto da regulação do Ensino Superior brasileiro. A seguir, apresentaremos uma síntese da análise dos dados obtidos a partir da aplicação do questionário que teve a finalidade de medir a percepção dos coordenadores de CPA soteropolitanas, no que diz respeito à participação dessas comissões no processo de regulação.

\section{Desenvolvimento Metodológico da Pesquisa}

Para o desenvolvimento da pesquisa, foi elaborado um questionário original contendo 18 questões. Adotamos como referência para aplicação desse questionário a totalidade de coordenadores de CPA constituídas em IESP da cidade de Salvador, ou seja, 46 sujeitos. Deste universo obtivemos o retorno de 42 respondentes. Nossa pesquisa abrangeu, portanto, 91,3\% do universo total, o que a qualifica como bastante representativa. 
Quanto à percepção dos coordenadores em relação à natureza da CPA, 79\% dos sujeitos concordam que a comissão é um importante órgão que proporciona a participação social na regulação do ensino superior, enquanto $7 \%$ discordam e $14 \%$ se colocam indecisos. De outra parte, $48 \%$ dos respondentes se colocam de forma indecisa quanto à participação da CPA na tomada de decisões relativas à regulação do ensino superior, enquanto 19\% discordam que isso ocorra e 33\% concordam. Esses dados nos levam a pensar que há um paradoxo, na medida em que, de um lado, existe um alto percentual de sujeitos que consideram a CPA como órgão de participação na regulação do ensino superior e, de outro, um percentual elevado de sujeitos demonstra dúvida quanto à participação efetiva da CPA na regulação.

No que tange à percepção dos sujeitos quanto à participação dos representantes de segmentos da comunidade acadêmica e sociedade civil organizada que integram a CPA, as respostas suscitaram reflexões importantes. A afirmação de que tais segmentos participam ativamente no processo de avaliação interna ensejou o seguinte resultado: (i) no caso da comunidade acadêmica, $49 \%$ se mostraram indecisos, enquanto $46 \%$ concordaram e apenas $5 \%$ discordaram; (ii) já em relação à sociedade civil organizada, $58 \%$ se mostraram indecisos, enquanto $22 \%$ discordaram e $20 \%$ concordaram. Esses dados nos conduzem à compreensão de que a participação social no desempenho da CPA apresenta-se de forma incipiente, uma vez que as questões relacionadas a este assunto ocasionaram resultados com grande incidência de sujeitos indecisos e discordantes. Podemos interpretar que há dificuldades para viabilizar a participação. Essa dificuldade pode estar associada à pouca cultura de participação nos processos de avaliação e regulação do ensino superior.

Outra interpretação que se coloca frente aos dados se refere à questão da autonomia da CPA. As dificuldades para viabilizar a atuação autônoma da CPA podem interferir de forma negativa na percepção que seus participantes têm do processo de participação. Alguns dos dados levantados a partir da percepção dos sujeitos podem reforçar tal interpretação, especialmente, aqueles que tratam especificamente da autonomia da Comissão, como veremos a seguir.

Quanto à autonomia da CPA em relação aos órgãos internos da IES, observase que $52 \%$ concordaram que a CPA funciona de forma autônoma, enquanto $30 \%$ expressaram indecisão, e 18\% discordaram, podendo indicar que a relação de autonomia entre CPA e IES se apresenta de forma parcial. O percentual acumulado de indecisos e discordantes fica muito próximo do percentual daqueles que concordam. É importante salientar que, além disso, dois dos respondentes preferiram não opinar, deixando em branco essa questão. 
No que concerne à relação de autonomia entre a CPA e o MEC, verifica-se que um percentual alto, $51 \%$, se colocou de forma indecisa, enquanto $37 \%$ concordaram que a Comissão atua de forma autônoma e $12 \%$ discordam. A partir dos dados, é possível inferir que os coordenadores de CPA percebem que há pouca autonomia da Comissão em relação ao MEC. Nesse caso, o grau de independência da CPA é ainda mais limitado que aquele percebido em relação à IES.

Outro aspecto que requer maior aprofundamento se refere à percepção dos respondentes quanto à atuação da CPA a partir das normas estabelecidas para seu funcionamento. Em geral, a percepção dos respondentes indica que a Comissão cumpre com suas funções de acordo com o que preconiza a norma legal. 86\% concordaram que tomada de decisão no âmbito da CPA baseia-se nas normas estabelecidas para seu funcionamento, $14 \%$ se colocam como indecisos e nenhum respondente discordou. Contudo, quando se trata do conhecimento das atribuições normativas da CPA por parte dos membros da Comissão, paradoxalmente, o percentual de indecisos foi elevado, 52\%, embora nenhum sujeito tenha discordado. Esses resultados podem levar ao entendimento de que os membros da CPA não têm participação significativa no desempenho das atribuições da Comissão, uma vez que não há segurança de que conheçam suas normas de funcionamento.

\section{Considerações Finais}

Observa-se, portanto, que as dificuldades identificadas na atuação da CPA podem estar relacionadas a três aspectos principais: (i) dificuldades em promover a participação social no âmbito da CPA; (ii) dificuldades em viabilizar a atuação autônoma da Comissão; (iii) pouca clareza quanto à relação entre as CPA e o processo de regulação. É importante ressaltar que os modelos de avaliação e regulação implantados a partir do SINAES ainda se encontram em estágio inicial. As CPA foram instituídas em 2004, e sequer foi concluído o primeiro ciclo do sistema de avaliação. É compreensível, portanto, que diante de uma situação ainda não consolidada os atores envolvidos tenham dificuldades para exercer suas atribuições.

Com efeito, os sujeitos da pesquisa apresentam uma percepção favorável em relação ao processo em que estão envolvidos por meio da CPA. Esse fato demonstra que, a despeito das contradições observadas, os coordenadores de CPA vêem de forma auspiciosa os caminhos trilhados até então. Constatamos, ainda, que há uma grande distância a ser percorrida no que diz respeito à constituição 
de um sistema de regulação cuja atuação privilegie, de fato, a participação social como princípio, embora haja sinais de que esse é um processo novo e em curso no cenário do ensino superior privado. Tais indícios podem ser observados a partir da iniciativa promovida pelo SINAES visando envolver a sociedade no processo de avaliação e regulação.

\section{Referências}

AGASIST, Tommaso; CATALANO, Giuseppe. Governance models of university systems: twards a quasi-markets? Tendencies and perspectives. A European comparison. Journal of Higher Education Policy and Management, Routledge, v. 28, n. 3, p. 245-265, 2006.

BARROSO, João. A regulação das políticas públicas de educação: espaços, dinâmicas e actores. Lisboa: Educa \& Ui\&dCE, 2006.

. O estado, a educação e a regulação das políticas públicas. Educação e Sociedade, Campinas, v. 26, n. 92, p. 725-751, out. 2005. Especial.

BIRD. La enseñanza superior: las lecciones derivadas de la experiencia. Washington, [s. n], 1995.

BOBBIO, Norberto; MATEUCCI, Nicola; PASQUINO, Gianfranco. Dicionário de política. 12. ed. Brasília. UNB, 2002. v. 2, L-Z.

BONNIOL, Jean-Jaques; VIAL, Michel. Modelos de avaliação: textos fundamentais. Porto Alegre: Artmed, 2001.

BRASIL. MEC. Políticas e resultados, 1995-2002: ensino superior maior e melhor. Brasília, 2002

\section{- Diretrizes para a avaliação das instituições de educação}

superior. Brasília: CONAES, 2004.

. Plano nacional de educação. Brasília: INEP, 1998.

. Censo da Educação Superior 2004: Resumo Técnico.

Brasília: INEP, 2005. Disponível em $<$ http://www.inep.gov.br/download/ superior/2004/censosuperior/Resumo_tecnico-Censo_2004.pdf $>$. Acesso em jun. de 2007. 
BRESSER-PEREIRA, Luiz Carlos. Reforma do estado para a cidadania: a reforma gerencial brasileira na perspectiva internacional. São Paulo: Editora 34, 1998.

CUNHA, Luiz Antônio. Desenvolvimento desigual e combinado no ensino superior - Estado e mercado. Educação e Sociedade, Campinas, SP, v. 25, n. 88 , p.795-817, out. 2004. Especial.

CUNHA, Luiz Antônio. O ensino superior no octênio FHC. Educação e Sociedade, Campinas, SP, v. 24, n. 82, p.37-61, abr. 2003.

DIAS SOBRINHO, José. Avaliação ética e política em função da educação como direito público ou como mercadoria? Educação e Sociedade, Campinas, SP, v. 25, n. 88, p. 703-725, out. 2004. Especial.

HADDAD, Sérgio; GRACIANO, Mariângela. Educação: direito universal ou mercado em expansão. São Paulo em Perspectiva, São Paulo, v. 18, n. 3 , p. 67-77, jul./set. 2004.

KING, Roger. Analyzing the higher education regulatory state. Centre for the Analysis of Risk and Regulation. London: London School of Economics, 2006. Discussion Paper.

NUNES, Edson. Teias de relações ambíguas: regulação e ensino superior. Brasília: INEP, 2002.

PATEMAN, Carole. Participation and democratic theory. Cambridge: Cambridge University Press, 1970.

RANIERI, Nina Beatriz. Educação superior, direito e estado: na lei de diretrizes e bases (lei 9.394/96). São Paulo: Edusp; FAPESP, 2000.

SAMPAIO, Helena Maria Sant'Ana. O ensino superior no Brasil: o setor privado. São Paulo: Hucitec; FAPESP, 2000.

SILVA JUNIOR, João dos Reis. Pragmatismo e populismo na educação superior nos governos FHC e Lula. São Paulo: Xamã, 2005. 